Article

\title{
Atomistic Analysis of ToxN and ToxI Complex Unbinding Mechanism
}

\author{
Guodong $\mathrm{Hu}^{1, *}, \mathrm{Xiu}_{\mathrm{Yu}}{ }^{1}$, Yunqiang Bian ${ }^{1}$, Zanxia Cao ${ }^{1}{ }^{\mathbb{C}}$, Shicai Xu ${ }^{1}$, Liling Zhao ${ }^{1}{ }^{\mathbb{D}}$, \\ Baohua Ji ${ }^{1}$, Wei Wang ${ }^{2}$ and Jihua Wang ${ }^{1, *}$ \\ 1 Shandong Key Laboratory of Biophysics and Institutes of Biophysics, Dezhou University, Dezhou 253023, \\ China; m13723922800@163.com (X.Y.); bianyunqiang@163.com (Y.B.); qiayilai@mail.ustc.edu.cn (Z.C.); \\ xushicai001@163.com (S.X.); zhaoll@sina.com (L.Z.); jbh1971@126.com (B.J.) \\ 2 National Laboratory of Solid State Microstructure and Department of Physics, Nanjing University, \\ Nanjing 210093, China; wangwei@nju.edu.cn \\ * Correspondence: xzszhgd@163.com (G.H.); jhw25336@126.com (J.W.); Tel.: +86-534-898-7536 (G.H.); \\ +86-534-898-5933 (J.W.)
}

Received: 17 September 2018; Accepted: 2 November 2018; Published: 9 November 2018

\begin{abstract}
ToxIN is a triangular structure formed by three protein toxins (ToxNs) and three specific noncoding RNA antitoxins (ToxIs). To respond to stimuli, ToxI is preferentially degraded, releasing the ToxN. Thus, the dynamic character is essential in the normal function interactions between ToxN and ToxI. Here, equilibrated molecular dynamics (MD) simulations were performed to study the stability of ToxN and ToxI. The results indicate that ToxI adjusts the conformation of $3^{\prime}$ and $5^{\prime}$ termini to bind to ToxN. Steered molecular dynamics (SMD) simulations combined with the recently developed thermodynamic integration in $3 \mathrm{nD}$ (TI3nD) method were carried out to investigate ToxN unbinding from the ToxIN complex. The potentials of mean force (PMFs) and atomistic pictures suggest the unbinding mechanism as follows: (1) dissociation of the $5^{\prime}$ terminus from ToxN, (2) missing the interactions involved in the $3^{\prime}$ terminus of ToxI without three nucleotides (G31, A32, and A33), (3) starting to unfold for ToxI, (4) leaving the binding package of ToxN for three nucleotides of ToxI, (5) unfolding of ToxI. This work provides information on the structure-function relationship at the atomistic level, which is helpful for designing new potent antibacterial drugs in the future.
\end{abstract}

Keywords: ToxIN; unbinding mechanism; molecular dynamics simulation; steered molecular dynamics simulation

\section{Introduction}

Bacteria have evolved various phage-resistance mechanisms to resist bacteriophage infection [1]. Resistance strategies include the abortive infection (Abi) systems [2], which promote cell death and limit phage replication within a bacterial population. Abi can be mediated by a toxin-antitoxin (TA) pair [3,4], which is widespread throughout prokaryotes [5]. The TA pairs in bacteria maintain a stable dynamic balance in a common environment. When bacteria are in an adverse environment, the antitoxin with less stability is preferentially degraded in response to stimuli, which leads to toxin release from compound. Then, the free toxins in the cells can lead to bacterial altruistic death or resistance. TA pairs are classified into five types based on the mechanism by which the antitoxin inhibits toxin activity [6-8]. All share common features, in that they include a toxic protein that is usually bicistronic in architecture, but are distinguished from each other by the manner in which this toxic protein is antagonized [9]. In Type III, a small RNA interacts directly with the protein toxin to block its activity $[3,10]$. 
The first example of type III is the ToxIN system which is encoded by a cryptic plasmid of Erwinia carotovora subsp. atroseptica, pECA1039. This system consists of a protein toxin (ToxN) and a specific RNA antitoxin (ToxI) [3,4]. The crystal structure of the ToxIN complex determined by Blower et al. from Pectobacterium atrosepticum [11] is a triangular structure formed by extensive cross-interaction with a ToxN at each vertex of the triangle (Figure 1). ToxN has 162 amino acids, consisting of four alpha helices (H1-H4) and six antiparallel beta folds (S1-S6). ToxI, a 36-nucleotide noncoding RNA, folds as an interdigitated hairpin-type pseudoknot, seems to be vital for inhibition of the toxin and is entirely unique throughout known examples of TA systems [11].

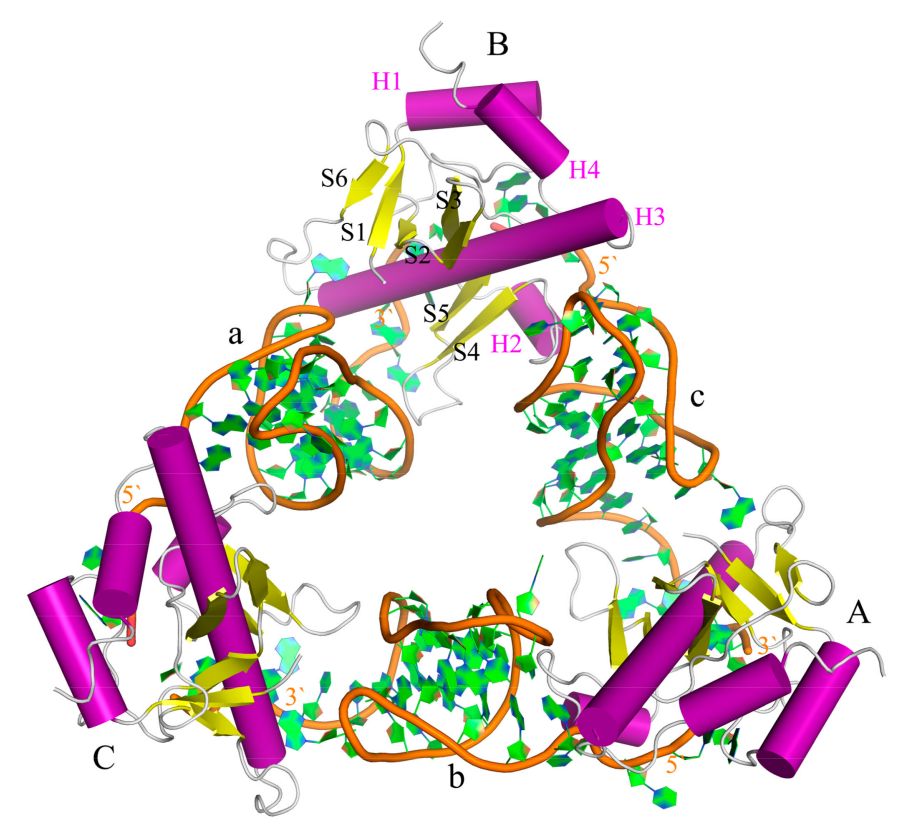

Figure 1. Structure of three protein toxins and three noncoding RNA antitoxins complex (ToxIN) shown in cartoon representation. Three ToxNs (protein toxins) and ToxIs (specific RNA antitoxins) are labeled with uppercase and lowercase letters, respectively. Secondary structures of ToxN(B) are also labeled with $\alpha$-helices $\mathrm{H} 1$ to $\mathrm{H} 4$ and $\beta$-strands S1 to S6.

RNA pseudoknots, one of the most prevalent motifs, have been found to play a variety of diverse roles in biology. These roles include forming the catalytic core, self-splicing introns, and altering gene expression by inducing ribosomal frame shifting in many viruses [12-15]. Moreover, pseudoknots have been artificially developed to bind specific small molecules [16] and even to inhibit proteins such as the HIV-1 reverse transcriptase [17]. G5 is a key determinant of the pseudoknot fold. Mutagenesis studies have corroborated its importance by the loss of antitoxicity with a ToxI G5A mutation [11].

The crystallographic structure shows extensive interactions between ToxN and ToxI, which play a vital role for abortive infection activity and maintenance of the complex in the cell. As suggested by Blowser et al. [11], evaluating the binding model ToxN and ToxI would be helpful to understand the protein-noncoding RNA pseudoknot interactions and potentially exploit the specific molecular recognition for therapeutic applications. Understanding how the ToxIN complex accomplishes its functions will necessarily involve the understanding of interactions and binding/unbinding at the atomistic level [18]. Molecular dynamics (MD) simulations could serve as a powerful tool for understanding the structure-function relationship of macromolecules [19-21]. Estarellas et al. have carried out a series of explicit solvent MD simulations of the Csy4/RNA RNP complex [22]. Wang's group have investigated the binding-induced conformational changes in the recognition of the 5S RNA by the three central zinc fingers of protein TFIIIA [23]. Molecular dynamics simulations test minute changes, ascertain the dynamical properties of the system, and provide more accurate structural ensembles [24-29]. Even so, it is still difficult for equilibrated MD simulation to observe 
large conformational changes, especially for the unbinding of large complexes. Steered molecular dynamics (SMD) simulations take inspiration from single-molecule pulling experiments [30], and dissociate a complex structure by a pulling force [31,32]. SMD simulations have become widely used in studying many biochemical processes, including the transportation of ions and organic molecules across membrane channels [33-37] and protein unfolding/folding mechanisms [38], as well as the mechanisms of protein-ligand binding [31,39-41].

In the current work, we carried out three $1 \mu \mathrm{s}$ MD simulations on ToxI, ToxN, and their complex. The conformational differences of ToxI and ToxN in monomer and in complex were investigated by the root mean square deviations (RMSDs) and principal component (PC) analyses. We also studied the function of nucleotide G5 in ToxI by the comparison of wild-type ToxI and its two mutations of G5. Steered molecular dynamics (SMD) simulations and potentials of mean force (PMFs) were used to evaluate the unbinding of ToxIN.

\section{Results and Discussion}

\subsection{Stability of the Systems}

To evaluate the stability of the MD simulations, we calculated the RMSD values of these structures in MD simulations with respect to their original structures. Figure 2 shows the RMSDs and the radius of gyration $(\mathrm{Rg})$ versus the MD simulation time for one of three MD simulations. This confirms that all systems were in stable states after $700 \mathrm{~ns}$ MD simulation time. The last $300 \mathrm{~ns}$ of MD trajectories were used for subsequent analysis. The comparative plots of the RMSDs reveal that the RMSD values for ToxN were significantly larger in monomer (apo-ToxN) than in complex (com-ToxN), and the same was true for ToxI. The fluctuation of the RMSD values were also much higher in the apo-ToxI and apo-ToxN ( $\sigma=0.47$ and 0.16$)$ than in the com-ToxI and com-ToxN ( $\sigma=0.24$ and 0.12). On the other hand, the average values of $\operatorname{Rg}$ of ToxI for monomer $(\sigma=0.17)$ were smaller than those for complex $(\sigma=0.41)$, suggesting a compact and stable change from complex to monomer. Then, apo-ToxI underwent large conformational changes during the MD simulation process starting from com-ToxI conformation, which is also in agreement with the fact that the protein or RNA do not necessarily adopt their lowest potential energy conformation when forming a complex. ToxI is a pseudoknot with two single-stranded tails interacting with ToxN in complex. To find out which parts of ToxI change, we calculated the RMSDs of ToxI for nucleotides from 5 to 31. The average RMSD over the last $300 \mathrm{~ns}$ MD simulation trajectories for the whole ToxI $(7.04 \AA)$ were much larger than for ToxI (5-31) (2.34 $\AA$ ), indicating that two tails changed substantially relative to the pseudoknot in the monomer.

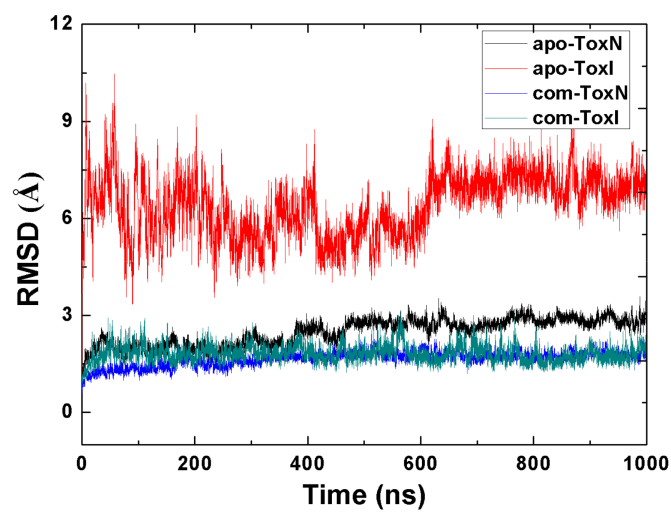

(A)

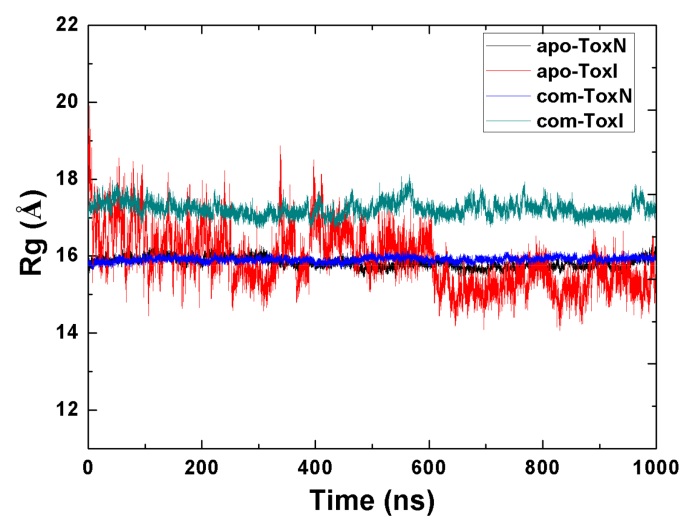

(B)

Figure 2. (A) The root mean square deviations (RMSDs) of the selected atoms with respect to their crystal structures as a function of molecular dynamics (MD) simulation time. (B) Radius of gyration as a function of MD simulation time. The prefix "apo" refers to the monomer form, and "com" refers to the complexed form. 
PC analyses were also performed based on the last 300 ns MD simulation trajectory. Figure S1 shows plots of the eigenvalues obtained from the diagonalization of the covariance matrix of the fluctuations of chosen atoms $\mathrm{C} \alpha$ for ToxN and atoms ( $\left.\mathrm{P}, \mathrm{O}^{\prime}, \mathrm{O}^{\prime}, \mathrm{C}^{\prime}, \mathrm{C}^{\prime}, \mathrm{C}^{\prime}\right)$ for ToxI, depicted in decreasing order versus the corresponding eigenvector indices. The magnitudes of the eigenvalues of ToxI and ToxN in bound state were lower. The first five principal components (PCs) accounted for $54.7 \%, 49.7 \%, 78.2 \%$, and $68.0 \%$ for apo-ToxN, com-ToxN, apo-ToxI, and com-ToxI, respectively. The first eigenvalues, which are relative to concerted motions, decreased quickly in amplitude and reached a constrained number, indicating more localized fluctuations rather than global fluctuations in the MD simulations.

\subsection{The Interaction between ToxI and ToxN}

To evaluate the interaction between ToxI and ToxN from the energetic viewpoint, we have calculated the binding free energy between each residue and ToxI, as well as between each nucleotide and ToxN by utilizing the free energy decomposition method. The key residues and nucleotides are shown in Figure 3. Fourteen residues of ToxN interacted with ToxI with large favorable energies and five residues with unfavorable energies $\left|\Delta G_{\text {residue-ToxI }}\right| \geq 5 \mathrm{kcal} / \mathrm{mol}$ (Table S1). These residues were located at the interaction surface between ToxN and ToxI (Figure 3A). Note that these residues were either polar or charged, with the exception of Met11. The decomposition method demonstrates that the main energy terms of these residues are from the electrostatic 3 contribution, except Met113 is mainly driven by the van der Waals energy. The charged residues are divided into two groups. One group has positive charges including lysine and arginine residues, which provide a favorable contribution. The other group including negative charge aspartic acid and glutamic acid contribute unfavorably. These polar or charged residues form a hydrophilic groove interacting with the $3^{\prime}$ terminus of ToxI and the $5^{\prime}$ terminus of another ToxI.

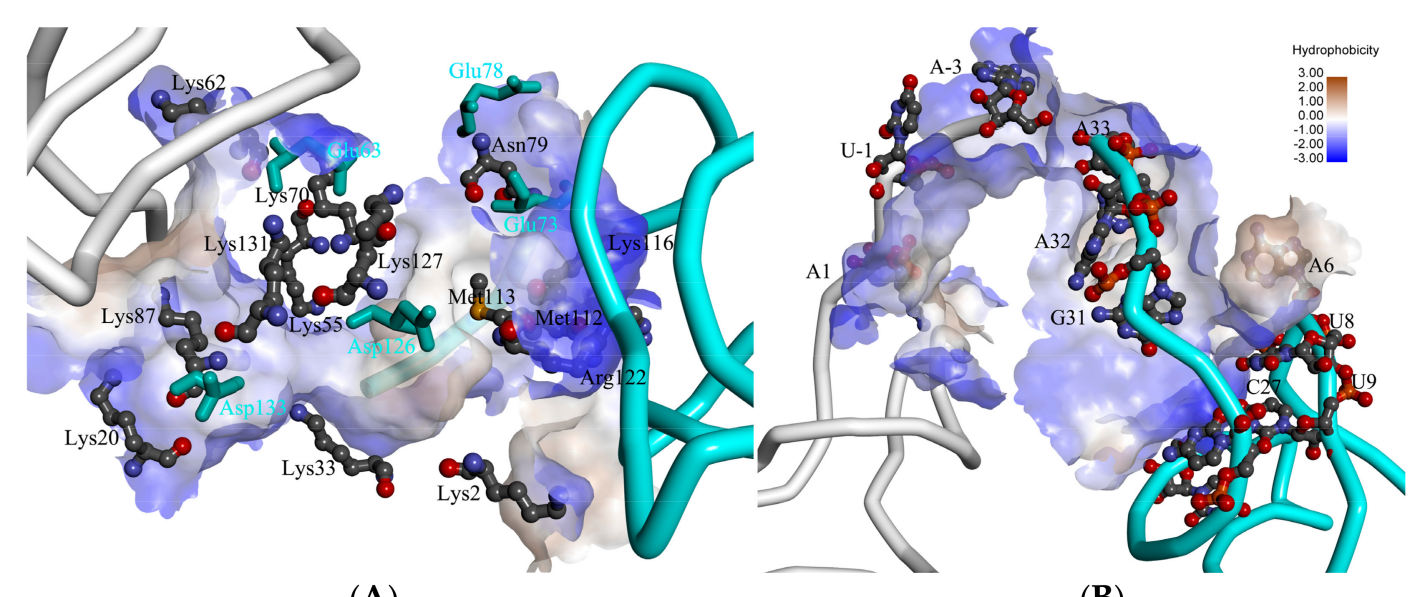

(A)

(B)

Figure 3. The key residues (A) and nucleotides (B) for the ToxN and ToxI interaction. The interaction surfaces are shown in hydrophobic surface. The structures of ToxN and ToxI are shown in white or pale cyan colors with tube representation. The key residues and nucleotides with favorable contribution are shown in ball and stick representation, and residues with unfavorable contribution are shown in stick representation with cyan color.

Ten nucleotides of ToxI interact with ToxN with large favorable energies for $\left|\Delta G_{n u c l e o t i d e-T o x N}\right|$ $\geq 3 \mathrm{kcal} / \mathrm{mol}$ (Figure 3B and Table S1). The large favorable gas-phase electrostatic contributions were compensated by the unfavorable polar solvation energy. There were only two nucleotides with favorable electrostatic contribution. The non-polar contribution would be the main driving force for the binding of ToxI to ToxN. 


\subsection{The Function of $G 5$}

The crystallographic structure shows that G5 interacts with G21 and U22 by stable hydrogen bonds (H-bonds) between their nitrogenous bases. To evaluate these interactions' function in the ToxIN complex, we analyzed these H-bonds and calculated the distances between two nitrogenous bases based on our three $1 \mu \mathrm{s}$ MD simulations for ToxIN, as well as for ToxI. Two nitrogen atoms of the nitrogenous base of G5 formed H-bonds with the oxygen atoms of the backbone of G21, as well as U22. The two H-bonds of G5 (hb1 and hb2) were weaker in com-ToxI than in apo-ToxI (hb3 and $\mathrm{hb} 4$ ) for the rising occupancies, and two new H-bonds (hb5 and hb6) were formed with higher occupancy between G5 and G23 (Figure 4A). The distances between the mass center of the nitrogenous base of G5 and G21/U22 in apo-ToxI were slightly different from those in com-ToxI (Figure 4B). These interactions are key for the stability of the pseudoknot. G5 also interacted with U8 by $\pi-\pi$ stacking. The average distance between the mass centers of the nitrogenous base of G5 and U8 in com-ToxI was $3.86 \AA$, which is much smaller than in apo-ToxI (Figure 4B). These interactions bring out bulged loops, exposing A6 which inserts the hydrophobic pocket formed by residues Phe3, Leu99, Leu100, Leu102, and Leu118 (Figure 3B and Figure S2). The free energy analysis also gave a large binding free energy of $-7.66 \mathrm{kcal} / \mathrm{mol}$ with favorable nonpolar interaction. This may imply that the loop conformation facilitates its interaction with ToxN rather than located at the energy minimum.

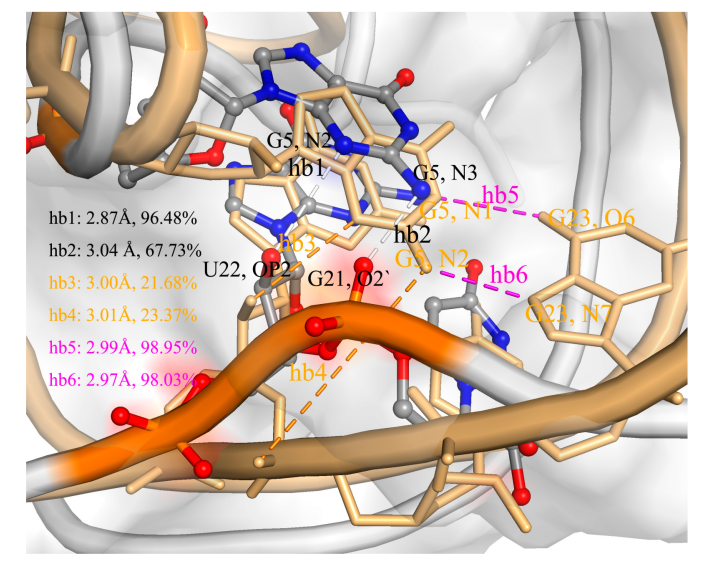

(A)

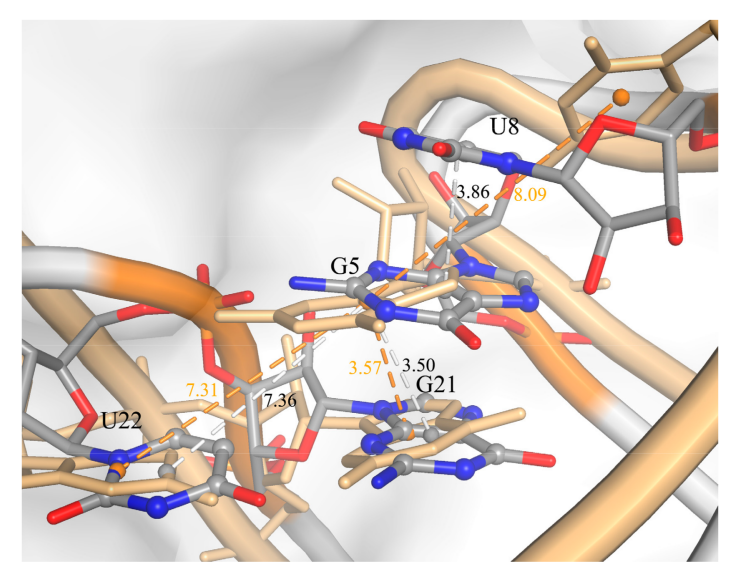

(B)

Figure 4. (A) The H-bonds formed for G5 in com-ToxI and in apo-ToxI. (B) The distances between the mass center of nitrogenous base of U8 and G5. The nucleotides are shown in ball and stick representation and colored with elements in com-ToxI, as well as stick representation in apo-ToxI. The H-bonds were determined by an acceptor $\cdots$ donor distance less than $3.5 \AA$ and an acceptor $\cdots H$ donor angle larger than $120^{\circ}$. Occupancy was defined as the percentage of the snapshots from MD simulation trajectory where a specific hydrogen bond exists.

The mutagenesis studies suggested that ToxI loses the antitoxicity in the G5A mutation [11]. To evaluate the structural influences on apo-ToxI, $1 \mu$ s MD simulations were carried out for G5A, as well as for $\mathrm{G} 5 \mathrm{H}$ with a hydrogen atom instead of the nitrogenous bases of G5. The RMSDs were calculated for the backbone atoms with nucleotide numbers from 5 to 31 relative to their starting structure of MD simulations (Figure 5A), as well as for the atoms which nucleotides within five angstroms (Figure 5B). It is clear that the plot of G5H was different from both of the other systems. The G5A system was in a stable state for the last $300 \mathrm{~ns}$ of the MD simulation. The distance between the mass center of the nitrogenous base of A5 and G21 was $3.80 \AA$ in G5A, which is a little larger than in G5 (3.60 $\AA$ ). The same condition was also found for the distance from the mass centers of nitrogenous base of G5/A5 to U22 (6.95 $\AA$ in G5 and 7.47 $\AA$ in G5A). This all indicates that G5 is much more compact than G5A. The results are also suggested by the average Rg of nucleotides $5-31$, which are 12.28 and 
$12.99 \AA$ in G5 and G5A, respectively. In the G5H, the interaction of nitrogenous base was lost and the average Rg of nucleotides 5-31 was $13.42 \AA$.

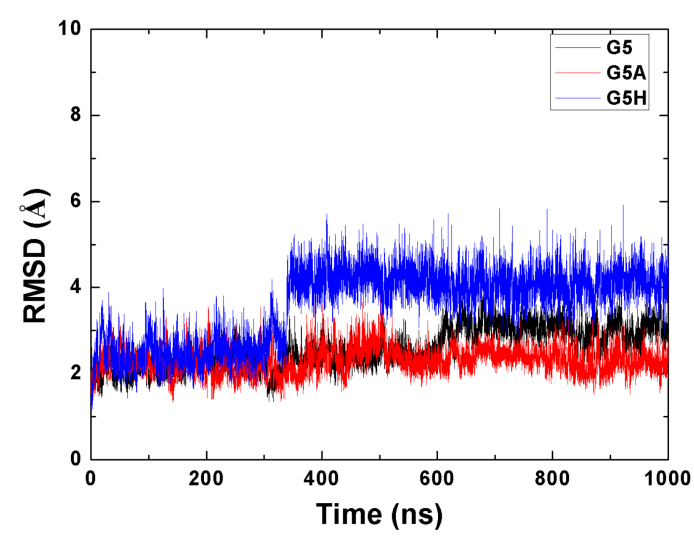

(A)

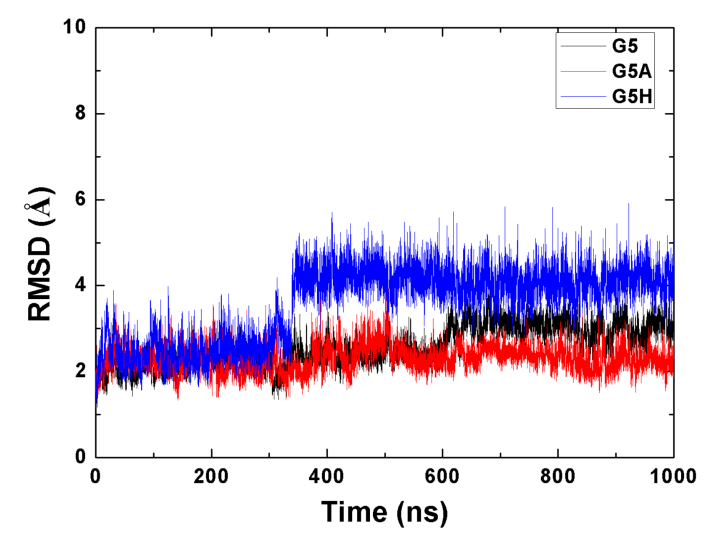

(B)

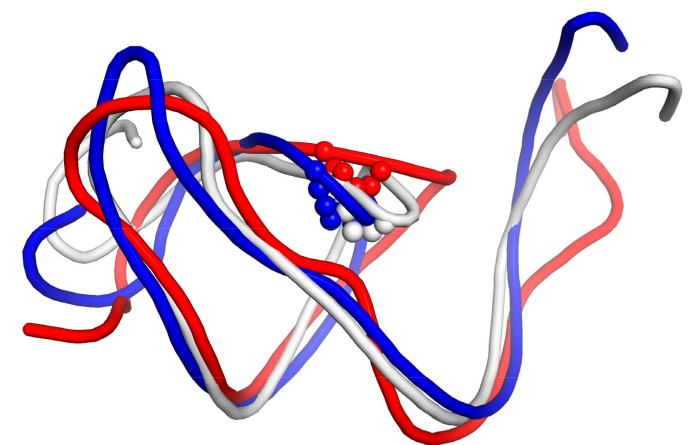

(C)

Figure 5. The RMSDs were calculated for the backbone atoms with the nucleotide numbers from 5 to 31 (A) relative to their original structure, and (B) for the atoms with nucleotides within $5 \AA$. (C) Superimposition of the representative structures of G5 (ToxI monomer in white color), G5A (mutated G5 to A5 in red color), and G5H (a hydrogen atom instead of nucleobase of G5 in blue color). Six atoms, which can show the position of nucleotide 5 , are shown in ball representation.

Clustering of trajectories was performed with cpptraj [42] using the hierarchical agglomerative approach clustered on $\mathrm{P}, \mathrm{O}^{\prime}, \mathrm{O}^{\prime}, \mathrm{C}^{\prime}, \mathrm{C}^{\prime}$, and $\mathrm{C}^{\prime}$ atoms of nucleotides using the average distance between members of two clusters. A total of 4000 frames from the last 200 ns were used to cluster with a "sieve" value of 10 . The most populated clusters accounted for $52.7 \%, 74.1 \%$, and $83.6 \%$ for G5, G5A, and G5H, respectively. We superimposed the representative frame together as shown in Figure 5C. Large differences of nucleotides conformation were found nearby nucleotide 5, as well as for the few nucleotides in the $3^{\prime}$ and $5^{\prime}$ termini, implying that the mutations only influenced the nearby nucleotides' conformation when ToxI was in the folded state.

\subsection{Induced-Fit Mechanism}

Clustering was performed on the combined trajectories-a total of 30,000 frames from three last-500-ns MD simulation trajectories by using a "sieve" value of 10 for apo-ToxI and apo-ToxN. Supplemental Table 2 shows the clustering results. The three most populated clusters accounted for $88.9 \%$ and $81.3 \%$ of all structures for ToxN and ToxI, respectively. Figure 6 shows the superimposition of the representative structures of the most populated clusters with their crystallographic structure. As shown in Figure 6A,B, the large differences between crystallographic structure and MD structures for ToxN were mainly in residues $23-33$ and 53-60, located at the binding pockets. 


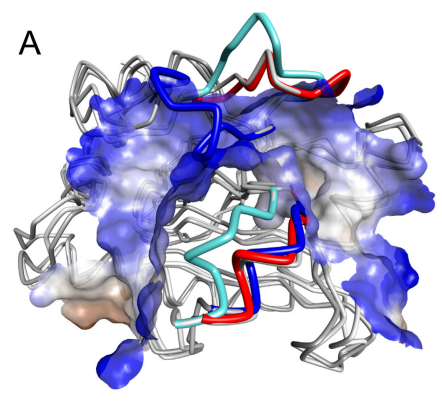

C

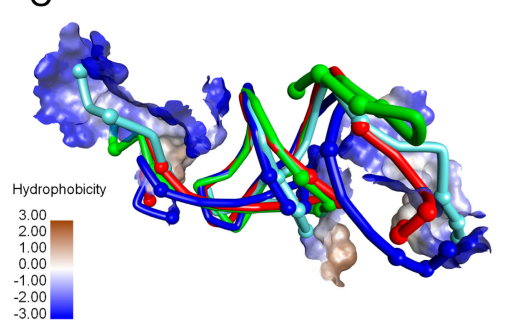

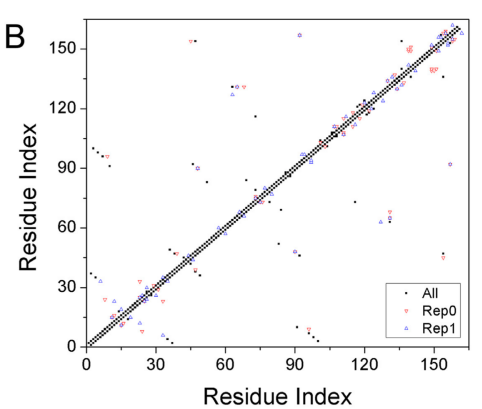

D

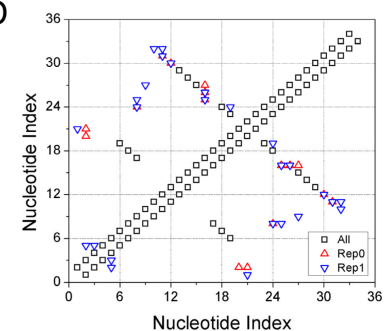

Figure 6. Superimposition of crystallographic structure and the representative structures from the clustering analysis for (A) apo-ToxN and (C) apo-ToxI. The interaction surfaces between ToxN and ToxI are shown in hydrophobic surface. All the structures are shown in tube representation. The different colors represent different conformations. The crystallographic structures are shown in pale cyan color. The nucleotides with different conformation in apo-ToxI are shown with an atom in a ball representation representing a nucleotide. Contact map based on the representative structures of clusters representative 0 (Rep0) and Rep1 for (B) ToxN and (D) ToxI Black squares represent the contacts that exist in both Rep0 and Rep1.

Up to now, two main hypotheses-"induced-fit" [40,43] and "conformational selection" [44] mechanisms-have been given to explain the coupling of ligand and protein folding. It is clear from Figure $6 \mathrm{C}, \mathrm{D}$ that the $3^{\prime}$ and $5^{\prime}$ termini of ToxI in the crystallographic structure differed in the three representative structures, is in accordance with the RMSDs analysis. The most favorable nucleotides were from the $3^{\prime}$ and $5^{\prime}$ termini based on the interaction energy analysis. Therefore, the folded apo-ToxI cannot directly bind to ToxN. We can suppose that the ToxN recognizes the ToxI with the "induced-fit" mechanism rather than the "conformational selection" mechanism $[23,40,45]$. The shift of $3^{\prime}$ and $5^{\prime}$ termini would be the predominant mechanism for ToxI binding to the groove of ToxN with an "induced-fit" mechanism.

\subsection{The Dissociation of ToxN(A) from the ToxIN Complex}

The ToxIN complex releases ToxN to realize its bio-function. To evaluate the detailed binding information, we carried out an SMD simulation for ToxN unbinding from the ToxIN complex. In the SMD simulations, ToxN(A) was dragged with three centers and the other two ToxNs were fixed with the $\mathrm{C} \alpha$ atoms (Figure 7A). SMD simulation has been widely used for extensive study of protein mechanical stability and protein-protein binding [38,46]. Previous SMD predictions agreed well with atomic force microscopy (AFM) observations [47]. In the implementation of SMD, the starting structures were rotated for ToxN(A) pointing to the $+\mathrm{z}$ direction, and the coordinates of three chosen $\mathrm{C} \alpha(\mathrm{Asn} 59 \mathrm{C} \alpha, \operatorname{Tyr} 115 \mathrm{C} \alpha$ and Asp133C $\alpha$ ) atoms represented the position and orientation of ToxN(A). To evaluate the convergence behavior, two simulation runs were carried out and the PMFs along the displacement are illustrated in Figure 7B. It is clear that the SMDs were convergent. The PMFs increased smoothly, so there would be no clear conformational change during the dissociation. 


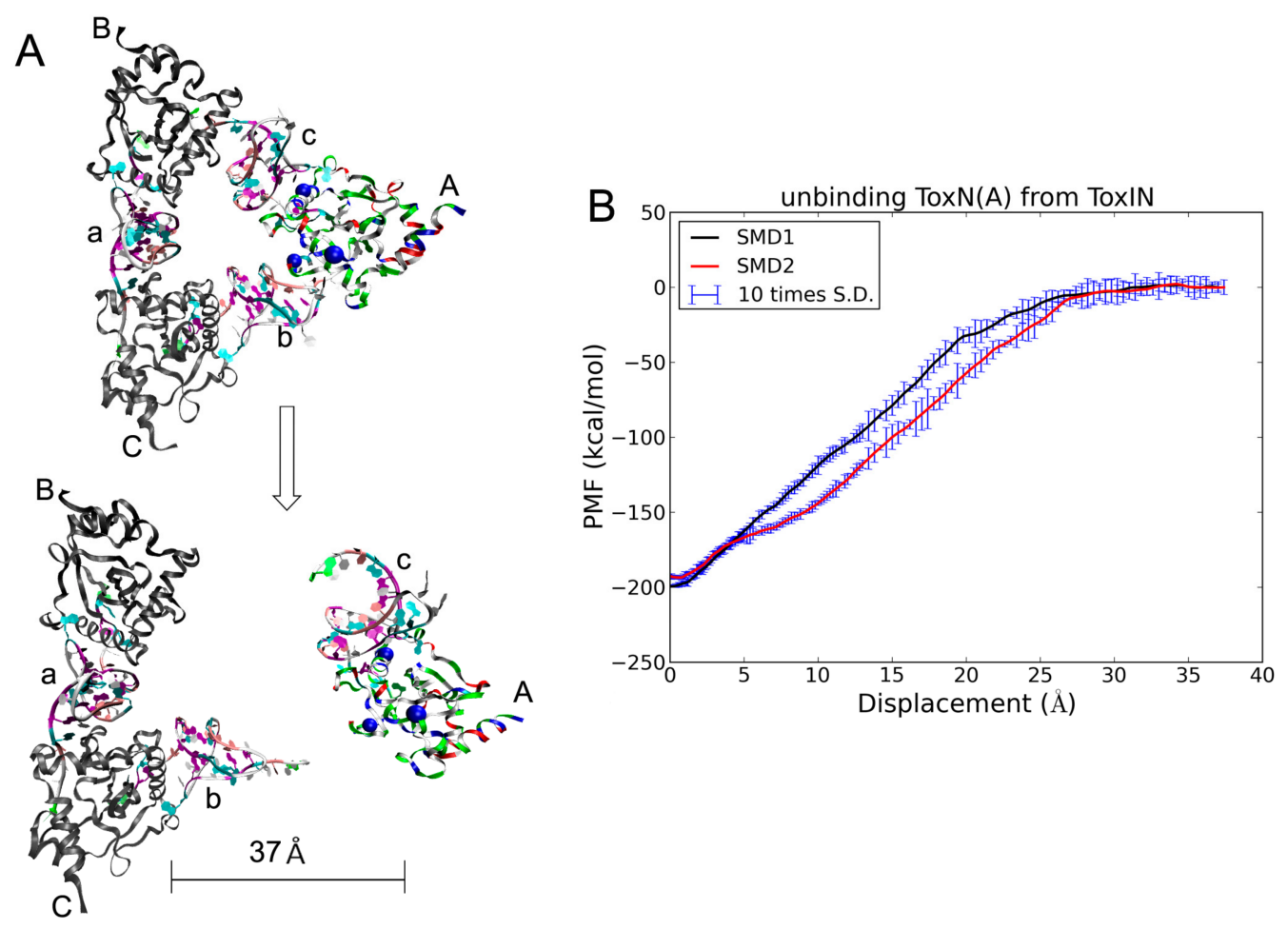

Figure 7. (A) The ToxIN in bound state (top) and in the unbound state (bottom). ToxN are shown in ribbons presentation. The dragged Tox $\mathrm{N}$ is colored by residue types. The fixed two ToxNs are colored in gray. Three ToxIs are colored by nucleotide name. The three centers are marked as blue balls. (B) The potential of mean force (PMF) curves of unbinding ToxN from its complex. SMD: steered molecular dynamics.

As shown in Figure 7A, ToxI(c) moved together with the dragged ToxN(A) during the SMD process, and $\operatorname{ToxI}(\mathrm{b})$ interacted with the fixed $\operatorname{ToxN}(\mathrm{C})$, indicating that ToxN interacted more strongly with the $3^{\prime}$ terminus than with the $5^{\prime}$ terminus. This is in accordance with the binding free energy of each nucleotide. As for ToxI(c), only three of the ten key nucleotides interacted with ToxN(B) versus seven with ToxN(A) (Figure 3B). This also suggests that the stability of the pseudoknot is stronger than the binding between ToxN and the $3^{\prime}$ terminus of ToxI.

To investigate the detailed information of dissociation, we calculated the native binding contacts $(\mathrm{Qb})$ using the native contacts patch of the RMSD Trajectory Tool in VMD [48]. Two residues or nucleotides in different monomers are in native binding contact when their heavy atoms are closer than $3.5 \AA . \mathrm{Qb}(\mathrm{Ac})$ and $\mathrm{Qb}(\mathrm{Cb})$ are the binding contacts between ToxN and the $3^{\prime}$ terminus of ToxI. The plots of $\mathrm{Qb}(\mathrm{Ac})$ decreased significantly, but not $\mathrm{Qb}(\mathrm{Cb})$ in two SMD simulations (Figure $8 \mathrm{~A}$ and Figure $\mathrm{S3}$ ). This can be attributed to the slight fluctuation of ToxN(C) for fixed $\mathrm{C} \alpha$ in the SMD simulation. As shown in Figure 8B, the nucleotides of ToxI(b) involved in the native binding contacts can be roughly divided into two groups. One group (C11, U12, and A13) formed unstable Qb, disappearing at the beginning of $5 \AA$ displacement. The binding free energy analysis also showed that they are not the key nucleotides. The other group with stable $\mathrm{Qb}$ was composed of five nucleotides at the $3^{\prime}$ terminus. The $\mathrm{Qb}$ of this group reduced obviously at the $10 \AA$ displacement, disappearing completely at $20 \AA$. 


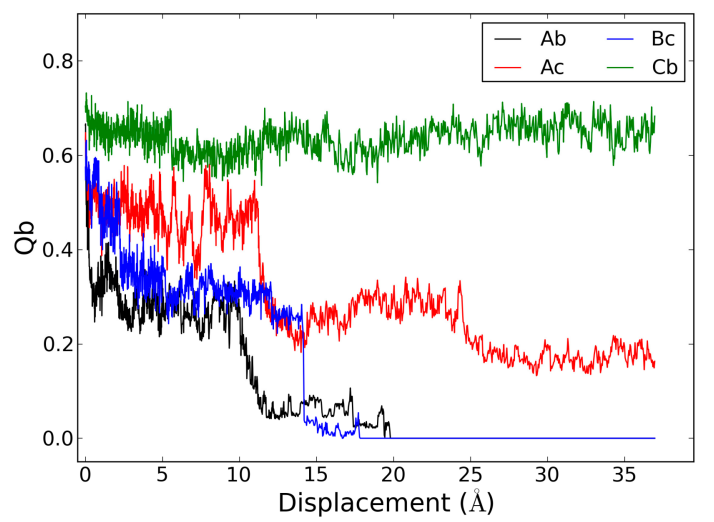

(A)

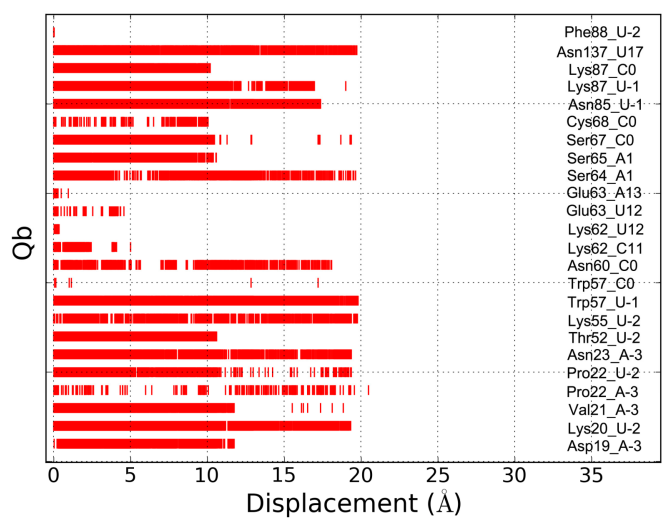

(B)

Figure 8. (A) Binding contact $(\mathrm{Qb})$ between ToxN and ToxI as a function of displacements. The uppercase and lowercase letters are for ToxN and ToxI, respectively. (B) The $\mathrm{Qb}$ of residue-nucleotide pair between $\operatorname{ToxN}(\mathrm{A})$ and $\operatorname{ToxI}(\mathrm{b})$ along the SMD1 simulation.

\subsection{The Dissociation of ToxI(c) from $\operatorname{Tox} N(A)$}

To evaluate the dissociation of ToxI(c) from ToxN(A), SMD simulations were also carried out for ToxI(c) dragged away ToxN(A) with two $\mathrm{C} \alpha$ atoms of Glu16 and Leu140 fixed. Three atoms (i.e., $\mathrm{C}^{\prime}$ atoms of G6, U13, and U20) were dragged for 56 A displacement. Figure 9 depicts the PMFs along the displacement for two runs. The unbinding could be roughly divided into three stages according to the PMFs. The first stage was the sharp increase from 2 to $13 \AA$ displacement for PMFs, indicating that a stable structural domain collapsed. The values of $\mathrm{Qb}$ gradually decreased from 0.5 to 0.15 , and the lines of RMSDs of ToxI were nearly level (Figure 9). Therefore, the collapsed structural domain was a section of the binding between ToxN and ToxI rather than unfolding of ToxI. In this stage, all the binding native contacts disappeared except for those involved in three nucleotides (A33, A32, G31) of the $3^{\prime}$ terminus. The second stage was from 13 to $37 \AA$ displacement, which showed a slight increase for PMFs. In this stage, ToxI was far away ToxN when the $3^{\prime}$ terminus was pulled tightly. The last stage was from $37 \AA$ to the end of SMD simulation. In this stage, the pseudoknot of ToxI started to unfold, for the RMSDs increased clearly and the distance between nucleotides U9 and G26 increased by $17 \AA$ from 23 to $40 \AA$ in SMD1 (Figure S4).

As shown in Figure 9, the ToxI(c) $3^{\prime}$ terminus was still bound to ToxN(A) after an SMD simulation of $56 \AA$ displacement. However, the SMD should be terminated because the water box was not large enough to hold the entire system for more pulling displacements. If we added the water box size, the more atoms in system would increase the computational cost. So, we divided the ToxN(A)-ToxI(c) system into two subsystems for small size according to the last structure from SMD1 of ToxN(A)-ToxI(c). One was the ToxN(A) and seven nucleotides from the $3^{\prime}$ terminus. The other was the ToxI(c) without the $3^{\prime}$ terminus. Figure 10 shows the PMF curves of unbinding and unfolding. The $3^{\prime}$ terminus of ToxI(c) moved out of the binding package of ToxN(A) at the $20 \AA$ displacement with a sharp increase of PMF. After that, the PMF increased slowly because there was some temporary interaction. As for the unfolding, the PMF increased obviously from 5 to $23 \AA$ displacement. In this stage, the helix near the $3^{\prime}$ terminus unfolded first, and the stable triplex structure was destroyed (Figure 10). After $23 \AA$ displacement, the PMF increased slowly with a large conformational change. The entire unfolding roughly followed an unzipping mechanism. The unfolding process described here is in accordance with Wang's work about pseudoknotted RNA unfolding [49]. So, the triplex structure is key for the unfolding of ToxI. The differences between the minimum and maximum of PMF were 73 and $57 \mathrm{kcal} / \mathrm{mol}$ for unfolding of the triplex structure in ToxI and the unbinding of seven nucleotides from the binding package of ToxN, respectively. Although the differences were larger than the real values, 
the condition for the unbinding SMD simulations were the same as the unfolding. These results may indicate an easy unbinding relative to the unfolding of ToxI [50].

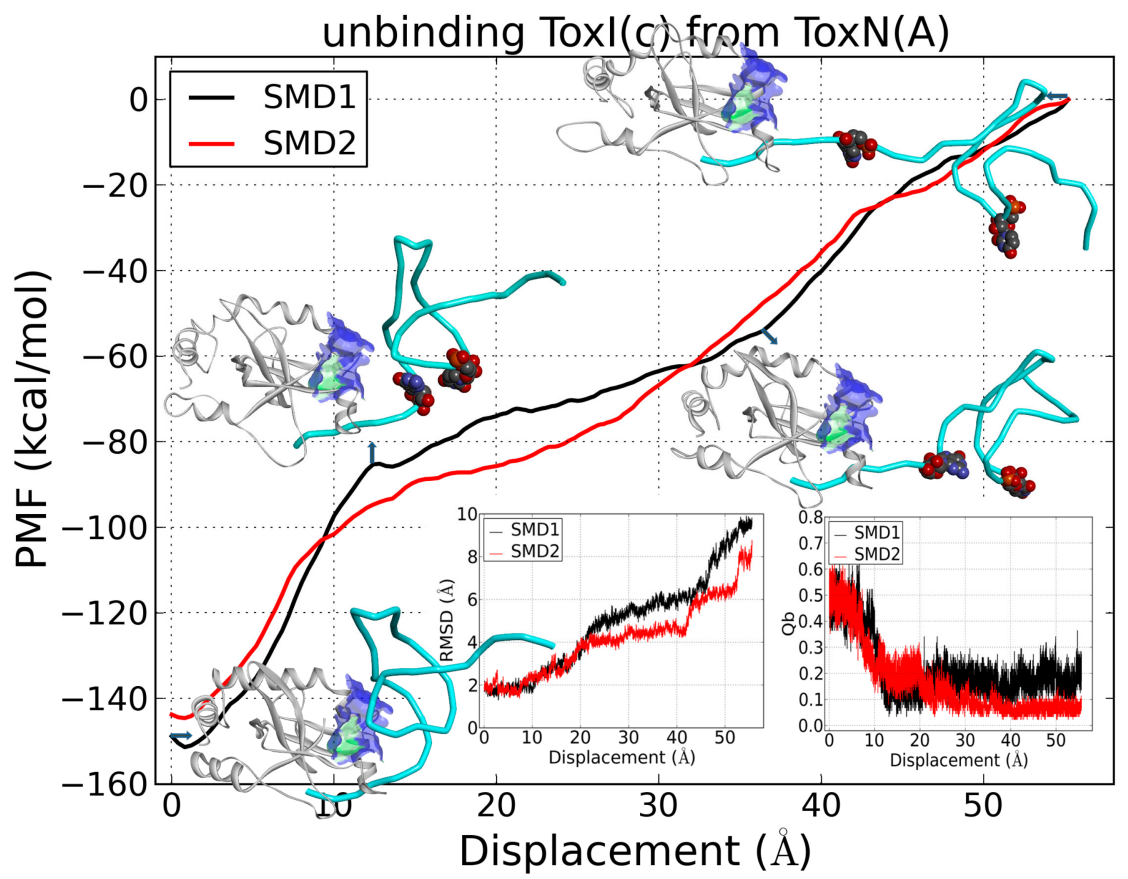

Figure 9. PMF curves of the unbinding of ToxI(c) from $\operatorname{ToxN}(\mathrm{A})$ in two SMD simulations. Insets: the $\mathrm{Qb}$ between ToxN and ToxI and RMSD of ToxI(c) as a function of displacements, the key structures of SMD1 from trajectories are shown. The structures of ToxN(A) are shown in white color with new cartoon representation, as well as ToxI(c) in cyan with tubes representation. A section of the interacting surfaces is shown. Nucleotides U9 and G26 are shown in ball representation.

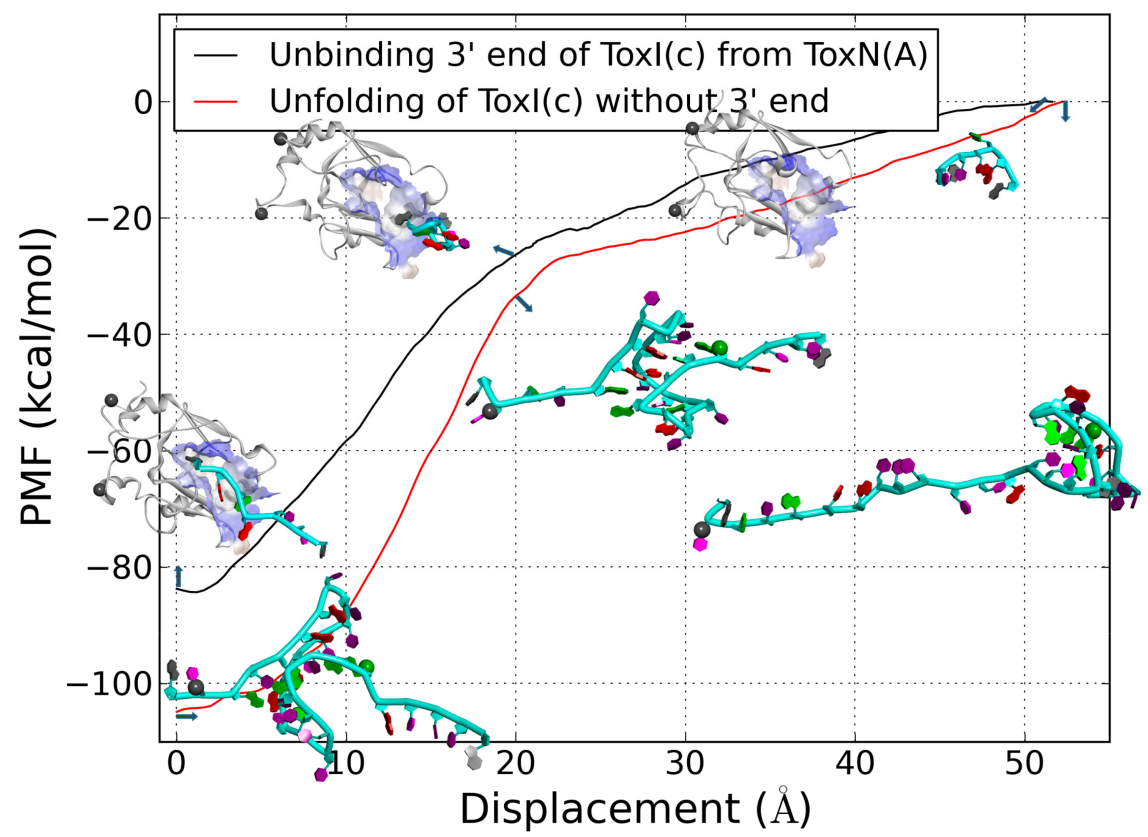

Figure 10. PMF curves of the unbinding of the $3^{\prime}$ terminus of ToxI(c) from ToxN(A) and the unfolding of ToxI(c) without the $3^{\prime}$ terminus. Insets: the starting, at displacement $20 \AA$, and the last structures are shown. The structures of $\operatorname{ToxN}(\mathrm{A})$ are shown in white color with new cartoon representation, as well as ToxI(c) in cyan with tubes representation and the nucleobase with rings. The atoms fixed in the SMD simulations are shown in grey color with balls. 


\section{Modelling and Simulation}

\subsection{Molecular Dynamics Simulations}

The initial structures of the MD simulations were extracted from the crystal structure of the ToxIN complex determined by Blower et al. (PDB ID: 2xdd) [11]. Independent MD simulations were carried out for the whole complex (ToxIN), ToxN and ToxI monomers (apo-ToxN and apo-ToxI), and the mutations of nucleotide G5 to A5 in ToxI monomer (G5A) as well as a hydrogen atom instead of the nitrogenous bases of G5 (G5H). SMD simulations were also performed for the ToxIN, protein ToxN(A), and RNA ToxI(c) complex (ToxN(A)-ToxI(c)), and two subsystems, ToxN(A)-3' terminus of ToxI(c) complex and ToxI(c) monomer. Table 1 lists the detailed information of these simulations, including total number of atoms, duration of the MD simulations, and the number of MD simulations.

Table 1. Systems for molecular dynamics (MD) simulations.

\begin{tabular}{cccc}
\hline System & Methods & Total Number of Atoms & MD Length (ns) \\
\hline ToxIN & Equilibrated MD & 93,408 & $1000 \times 3=3000$ \\
ToxI & Equilibrated MD & 26,478 & $1000 \times 3=3000$ \\
ToxN & Equilibrated MD & 19,351 & $1000 \times 3=3000$ \\
G5A & Equilibrated MD & 17,016 & 1000 \\
G5H & Equilibrated MD & 16,349 & 1000 \\
ToxIN & SMD & 115,152 & $338.8 \times 2=677.6$ \\
ToxN(A)-ToxI(c) & SMD & 50,534 & $338.8 \times 2=677.6$ \\
ToxN(A)-3' terminus of ToxI(c) & SMD & 43,306 & 338.8 \\
ToxI(c) & SMD & 38,519 & 338.8 \\
\hline
\end{tabular}

The crystallographic water molecules within $5 \AA$ of system were retained. The hydrogen atoms were added according to each residue's or nucleotide's default protonation states at a neutral $\mathrm{pH}$. All the systems were solvated in rectangular TIP3P water [51] boxes with the minimum solute-box boundary distance set to $10 \AA$. The appropriate numbers of counter-ions were added to neutralize the systems. The AMBER force field (FF12SB) [52,53] was used to describe the protein and RNA parameters, ions, and water molecules. The force field parameter of mutated nucleotide G5H was generated according to G5 parameters and modified the atoms' charge based on the RESP method [54] with the Antechamber module of the AMBER12 package.

The AMBER12 package [55] was used to perform all energy minimizations and MD simulations. We performed a two-step extensive energy minimization process by the steepest descent method and the conjugate gradient algorithm to relieve the bad contacts and to direct each system toward energetically favorable conformations. After minimization, each system was heated from 0 to $300 \mathrm{~K}$ over $70 \mathrm{ps}$, applying harmonic restraints with force constants of $2 \mathrm{kcal} /\left(\mathrm{mol} \cdot \AA^{2}\right)$ to all solute atoms. To adjust the solvent density, a constant-pressure MD simulation was carried out for 90 ps. Finally, constant-pressure MD simulation without any restraints for each system was carried out at $300 \mathrm{~K}$ with a Langevin thermostat and a target pressure $1.0 \mathrm{~atm}$ using isotropic positional scaling. The particle mesh Ewald method [56] was applied to treat the long-range electrostatic interactions with a cutoff of $12 \AA$ for all MD simulations. The SHAKE algorithm [57] was employed to treat the covalent bonds involving hydrogen atoms, and the time step was set to be $2 \mathrm{fs}$.

\subsection{Residue-Inhibitor Interaction Decomposition}

To understand the ToxN and ToxI interaction in more detail, the interaction energies between ToxN and each nucleotide of ToxI (as well as between ToxI and each residue of ToxN) were calculated using the theory of free energy decomposition [58]. This approach has been successful in the analysis of the interaction between protein and ligand or between protein and protein [59-61]. The binding interaction 
of each pair $\left(\Delta G_{\text {ToxN-nuc/ToxI-res }}\right)$ includes four terms: van der Waals energy $\left(\Delta E_{v d w w}\right)$, electrostatic energy $\left(\Delta E_{\text {ele }}\right)$, polar solvation contribution $\left(\Delta G_{\text {pol }}\right)$, and nonpolar solvation contribution $\left(\Delta G_{\text {nonpol }}\right)$ :

$$
\Delta G_{\text {ToxN-nuc/ToxI-res }}=\Delta E_{\text {ele }}+\Delta E_{\text {vdw }}+\Delta G_{\text {pol }}+\Delta G_{\text {nonpol }}
$$

All energy components were calculated using 150 snapshots extracted evenly from the last $300 \mathrm{~ns}$ of the MD simulation. $\Delta E_{v d w}$ and $\Delta E_{\text {ele }}$ were calculated with the same parameter as the MD simulation, and $\Delta G_{p o l}$ was calculated by generalized Born (GB) methods implemented in SANDER. $\Delta G_{\text {nonpol was }}$ determined with the equation $\Delta G_{\text {nonpol }}=\gamma S A S A+\beta$, where SASA is the solvent-accessible surface area that was determined using the LCPO model [62]. The values $\gamma$ and $\beta$ are the empirical constants, and were set $0.005 \mathrm{kcal} /\left(\mathrm{mol} \cdot \AA^{2}\right)$ and 0 , respectively [63].

\section{3. $S M D$ and $P M F$ in $3 n D$}

The SMD simulations were performed with the modified NAMD $2.13[64,65]$ with a larger margin of water box than the equilibrated MD simulation in the steered direction. The force field was the same as the equilibrated MD simulation. The systems were put in a box of water and neutralized. The displacement for the whole SMD simulation was divided into multi-windows, every $0.1 \AA$ from 0 to 5 $\AA$, every $0.2 \AA$ from 5 to $13 \AA$, and every $0.4 \AA$ from $13 \AA$ to the end. At each of the displaced positions, 2 ns equilibrated MD simulations were carried out with the steered centers and selected atoms fixed, then four sets of data of the forces acting on the steered centers were collected from four segments of unbiased MD runs in order to obtain the PMFs with the TI3nD method [64,66,67].

The PMF in $3 n$ dimensions ( $3 \mathrm{nD}), W\left[r_{1}, r_{2}, \ldots, r_{n}\right]$, is a function of the $3 \mathrm{n}$ coordinates of $n$ centers $\left(r_{1}, r_{2}, \ldots, r_{n}\right)$ along a single curve/line $u(\lambda)=\left(r_{1}(\lambda), r_{2}(\lambda), \ldots, r_{n}(\lambda)\right)$ connecting one state $u(0)=\left(r_{10}, r_{20}, \ldots, r_{n 0}\right)$ that is arbitrarily chosen from the bound state ensemble to the corresponding one state $u(1)=\left(r_{1 \infty}, r_{2 \infty}, \ldots, r_{n \infty}\right)$ that belongs to the dissociated state ensemble. The $3 \mathrm{nD}$ PMF difference between two states is equal to the line integral of the mean force acting the $3 \mathrm{n}$ degrees of freedom along a line connecting the two states. Since PMF is a function of state, any one line/curve connecting the two end states is necessary and sufficient for the computation in a straightforward extension of the well-known thermal integration thermodynamic integration in $3 \mathrm{nD}$ (TI3nD) given by the following formula $[64,66,67]$ :

$$
W\left[r_{10}, r_{20}, \ldots r_{n 0}\right]-W\left[r_{1 \infty}, r_{2 \infty}, \ldots r_{n \infty}\right]=\int_{\lambda=0}^{\lambda=1} d \mathbf{u}(\lambda) \cdot\left\langle-\frac{\partial H}{\partial \mathbf{u}}\right\rangle_{\mathbf{u}(\lambda)}
$$

where $H$ is the Hamiltonian of the entire system, a function of $3 N$ coordinates $\left(r_{1}, r_{2}, \ldots, r_{n} ; r_{n+1}, r_{n+2}, \ldots, r_{N}\right)$ of all the $N$ atoms of a model system.

\section{Conclusions}

Long time MD simulations were used to study the stability of ToxN and ToxI monomers, as well as their complex. The results suggest that the monomers are less stable upon their complexation, especially for the $3^{\prime}$ and $5^{\prime}$ termini of ToxI. The stable H-bonds of nucleotide G5 formed with G21 and U22 in com-ToxI are adjusted in apo-ToxI. To evaluate the function of G5 on stability of ToxI, the MD simulations of mutation G5A and G5H indicate a conformational difference of nearby nucleotides effected by the mutation G5A. The flexible $3^{\prime}$ and $5^{\prime}$ termini adjust their conformation to match the groove of ToxN during the process of binding with an "induced-fit" binding mechanism. The energetic calculation shows nineteen key residues of ToxN and ten nucleotides of ToxI in the interaction between ToxN and ToxI. The SMD simulations combined with TI3nD method were applied to obtain the PMF and provided atomistic pictures for the unbinding of ToxIN complex. The unbinding follows five steps. Firstly, the $5^{\prime}$ terminus of ToxI dissociates from ToxN. Secondly, the interactions involved in the $3^{\prime}$ terminus of ToxI without three nucleotides (A33, A32, G31) are lost. Thirdly, ToxI start to unfold. Then three nucleotides (A33, A32, G31) of ToxI leave the binding pocket of ToxN. Lastly, ToxN is unfolded. 
Supplementary Materials: Supplementary materials can be found at http:/ / www.mdpi.com/1422-0067/19/11/ 3524/s1.

Author Contributions: Conceptualization, G.H., W.W., and J.W.; Methodology, G.H.; Formal analysis, Y.B., Z.C., and S.X.; Data curation, X.Y., L.Z., and B.J.; Writing—original draft preparation, G.H. and X.Y.; Writing-review and editing, G.H. and J.W.; Visualization, X.Y.

Funding: This research was funded by the National Natural Science Foundation of China, grant number 11447004 and 61671107, the Taishan Scholars Program of Shandong Province, and the Shandong Science and Technology Development Program, grant number ZR2014GNC110025.

Acknowledgments: The authors thank Liao Y. Chen for providing the modified NAMD software and the TI3nD program.

Conflicts of Interest: The authors declare no conflict of interest.

\section{References}

1. Labrie, S.J.; Samson, J.E.; Moineau, S. Bacteriophage resistance mechanisms. Nat. Rev. Microbiol. 2010, 8, 317-327. [CrossRef] [PubMed]

2. Sorek, R.; Kunin, V.; Hugenholtz, P. CRISPR—A widespread system that provides acquired resistance against phages in bacteria and archaea. Nat. Rev. Microbiol. 2008, 6, 181-186. [CrossRef] [PubMed]

3. Fineran, P.C.; Blower, T.R.; Foulds, I.J.; Humphreys, D.P.; Lilley, K.S.; Salmond, G.P. The phage abortive infection system, ToxIN, functions as a protein-RNA toxin-antitoxin pair. Proc. Natl. Acad. Sci. USA 2009, 106, 894-899. [CrossRef] [PubMed]

4. Blower, T.R.; Fineran, P.C.; Johnson, M.J.; Toth, I.K.; Humphreys, D.P.; Salmond, G.P. Mutagenesis and functional characterization of the RNA and protein components of the toxIN abortive infection and toxin-antitoxin locus of Erwinia. J. Bacterial. 2009, 191, 6029-6039. [CrossRef] [PubMed]

5. Pandey, D.P.; Gerdes, K. Toxin-antitoxin loci are highly abundant in free-living but lost from host-associated prokaryotes. Nucleic Acids Res. 2005, 33, 966-976. [CrossRef] [PubMed]

6. Schuster, C.F.; Bertram, R. Toxin-antitoxin systems are ubiquitous and versatile modulators of prokaryotic cell fate. FEMS Microbial. Lett. 2013, 340, 73-85. [CrossRef] [PubMed]

7. Mruk, I.; Kobayashi, I. To be or not to be: regulation of restriction-modification systems and other toxin-antitoxin systems. Nucleic Acids Res. 2014, 42, 70-86. [CrossRef] [PubMed]

8. Kedzierska, B.; Hayes, F. Emerging roles of toxin-antitoxin modules in bacterial pathogenesis. Molecules 2016, 21, 790. [CrossRef] [PubMed]

9. Rao, F.; Short, F.L.; Voss, J.E.; Blower, T.R.; Orme, A.L.; Whittaker, T.E.; Luisi, B.F.; Salmond, G.P. Co-evolution of quaternary organization and novel RNA tertiary interactions revealed in the crystal structure of a bacterial protein-RNA toxin-antitoxin system. Nucleic Acids Res. 2015, 43, 9529-9540. [CrossRef] [PubMed]

10. Short, F.L.; Pei, X.Y.; Blower, T.R.; Ong, S.L.; Fineran, P.C.; Luisi, B.F.; Salmond, G.P. Selectivity and self-assembly in the control of a bacterial toxin by an antitoxic noncoding RNA pseudoknot. Proc. Natl. Acad. Sci. USA 2013, 110, E241-E249. [CrossRef] [PubMed]

11. Blower, T.R.; Pei, X.Y.; Short, F.L.; Fineran, P.C.; Humphreys, D.P.; Luisi, B.F.; Salmond, G.P. A processed noncoding RNA regulates an altruistic bacterial antiviral system. Nat. Struct. Mol. Biol. 2011, 18, 185-190. [CrossRef] [PubMed]

12. Staple, D.W.; Butcher, S.E. Pseudoknots: RNA structures with diverse functions. PLoS Biol. 2005, 3, e213. [CrossRef] [PubMed]

13. Bian, Y.; Zhang, J.; Wang, J.; Wang, J.; Wang, W. Free energy landscape and multiple folding pathways of an H-type RNA pseudoknot. PLoS ONE 2015, 10, e0129089. [CrossRef] [PubMed]

14. Adams, P.L.; Stahley, M.R.; Kosek, A.B.; Wang, J.; Strobel, S.A. Crystal structure of a self-splicing group I intron with both exons. Nature 2004, 430, 45-50. [CrossRef] [PubMed]

15. Egli, M.; Minasov, G.; Su, L.; Rich, A. Metal ions and flexibility in a viral RNA pseudoknot at atomic resolution. Proc. Natl. Acad. Sci. USA 2002, 99, 4302-4307. [CrossRef] [PubMed]

16. Sussman, D.; Nix, J.C.; Wilson, C. The structural basis for molecular recognition by the vitamin B 12 RNA aptamer. Nat. Struct. Biol. 2000, 7, 53-57. [CrossRef] [PubMed]

17. Tuerk, C.; MacDougal, S.; Gold, L. RNA pseudoknots that inhibit human immunodeficiency virus type 1 reverse transcriptase. Proc. Natl. Acad. Sci. USA 1992, 89, 6988-6992. [CrossRef] [PubMed] 
18. McDowell, S.E.; Spackova, N.; Sponer, J.; Walter, N.G. Molecular dynamics simulations of RNA: An in silico single molecule approach. Biopolymers 2007, 85, 169-184. [CrossRef] [PubMed]

19. Shaw, D.E.; Maragakis, P.; Lindorff-Larsen, K.; Piana, S.; Dror, R.O.; Eastwood, M.P.; Bank, J.A.; Jumper, J.M.; Salmon, J.K.; Shan, Y.; et al. Atomic-level characterization of the structural dynamics of proteins. Science 2010, 330, 341-346. [CrossRef] [PubMed]

20. Best, R.B. Atomistic molecular simulations of protein folding. Curr. Opin. Struct. Biol. 2012, $22,52-61$. [CrossRef] [PubMed]

21. Chen, J.; Wang, J.; Zhu, W. Zinc ion-induced conformational changes in new Delphi metallo-beta-lactamase 1 probed by molecular dynamics simulations and umbrella sampling. Phys. Chem. Chem. Phys. 2017, 19, 3067-3075. [CrossRef] [PubMed]

22. Estarellas, C.; Otyepka, M.; Koca, J.; Banas, P.; Krepl, M.; Sponer, J. Molecular dynamic simulations of protein/RNA complexes: CRISPR/Csy4 endoribonuclease. Biochim. Biophys. Acta 2015, 1850, 1072-1090. [CrossRef] [PubMed]

23. Tan, C.; Li, W.; Wang, W. Localized frustration and binding-induced conformational change in recognition of 5S RNA by TFIIIA zinc finger. J. Phys. Chem. B 2013, 117, 15917-15925. [CrossRef] [PubMed]

24. Terakawa, T.; Takada, S. Multiscale ensemble modeling of intrinsically disordered proteins: p53 N-terminal domain. Biophys. J. 2011, 101, 1450-1458. [CrossRef] [PubMed]

25. Hu, G.; Ma, A.; Wang, J. Ligand selectivity mechanism and conformational changes in guanine riboswitch by molecular dynamics simulations and free energy calculations. J. Chem. Inf. Model. 2017, 57, 918-928. [CrossRef] [PubMed]

26. Chen, J.; Wang, X.; Zhu, T.; Zhang, Q.; Zhang, J.Z. A comparative insight into amprenavir resistance of mutations V32I, G48V, I50V, I54V, and I84V in HIV-1 protease based on thermodynamic integration and MM-PBSA methods. J. Chem. Inf. Model. 2015, 55, 1903-1913. [CrossRef] [PubMed]

27. Hermann, T.; Westhof, E. Simulations of the dynamics at an RNA-protein interface. Nat. Struct. Biol. 1999, 6, 540. [CrossRef] [PubMed]

28. Mackerell, A.D., Jr.; Nilsson, L. Molecular dynamics simulations of nucleic acid-protein complexes. Curr. Opin. Struct. Biol. 2008, 18, 194-199. [CrossRef] [PubMed]

29. Guo, J.X.; Gmeiner, W.H. Molecular dynamics simulation of the human U2B ${ }^{\prime \prime}$ protein complex with U2 snRNA hairpin IV in aqueous solution. Biophys. J. 2001, 81, 630-642. [CrossRef]

30. Grubmuller, H.; Heymann, B.; Tavan, P. Ligand binding: Molecular mechanics calculation of the streptavidin-biotin rupture force. Science 1996, 271, 997-999. [CrossRef] [PubMed]

31. Patel, J.S.; Berteotti, A.; Ronsisvalle, S.; Rocchia, W.; Cavalli, A. Steered molecular dynamics simulations for studying protein-ligand interaction in cyclin-dependent kinase 5. J. Chem. Inf. Model. 2014, 54, 470-480. [CrossRef] [PubMed]

32. Li, M.S.; Mai, B.K. Steered molecular dynamics-A promising tool for drug design. Curr. Bioinform. 2012, 7, 342.

33. Giorgino, T.; De Fabritiis, G. A high-throughput steered molecular dynamics study on the free energy profile of ion permeation through gramicidin A. J. Chem. Theory Comput. 2011, 7, 1943. [CrossRef] [PubMed]

34. Chen, L.Y. Glycerol modulates water permeation through Escherichia coli aquaglyceroporin GlpF. Biochim. Biophys. Acta 2013, 1828, 1786-1793. [CrossRef] [PubMed]

35. Henin, J.; Tajkhorshid, E.; Schulten, K.; Chipot, C. Diffusion of glycerol through Escherichia coli aquaglyceroporin GlpF. Biophys. J. 2008, 94, 832-839. [CrossRef] [PubMed]

36. Mai, B.K.; Viet, M.H.; Li, M.S. Top leads for swine influenza A/H1N1 virus revealed by steered molecular dynamics approach. J. Chem. Inf. Model. 2010, 50, 2236-2247. [CrossRef] [PubMed]

37. Mai, B.K.; Li, M.S. Neuraminidase inhibitor R-125489-A promising drug for treating influenza virus: Steered molecular dynamics approach. Biochem. Biophys. Res. Commun. 2011, 410, 688-691. [CrossRef] [PubMed]

38. Colizzi, F.; Perozzo, R.; Scapozza, L.; Recanatini, M.; Cavalli, A. Single-molecule pulling simulations can discern active from inactive enzyme inhibitors. J. Am. Chem. Soc. 2010, 132, 7361-7371. [CrossRef] [PubMed]

39. Nicolini, P.; Frezzato, D.; Gellini, C.; Bizzarri, M.; Chelli, R. Toward quantitative estimates of binding affinities for protein-ligand systems involving large inhibitor compounds: A steered molecular dynamics simulation route. J. Comput. Chem. 2013, 34, 1561-1576. [CrossRef] [PubMed] 
40. Qin, F.; Jiang, Y.; Chen, Y.; Wu, M.; Yan, G.; Ye, W.; Li, Y.; Zhang, J.; Chen, H.F. Conformational selection or induced fit for Brinker and DNA recognition. Phys. Chem. Chem. Phys. 2011, 13, 1407-1412. [CrossRef] [PubMed]

41. Hu, G.; Xu, S.; Wang, J. Characterizing the free-energy landscape of MDM2 protein-ligand interactions by steered molecular dynamics simulations. Chem. Biol. Drug Des. 2015, 86, 1351-1359. [CrossRef] [PubMed]

42. Roe, D.R.; Cheatham, T.E., 3rd. PTRAJ and CPPTRAJ: Software for processing and analysis of molecular dynamics trajectory data. J. Chem. Theory Comput. 2013, 9, 3084-3095. [CrossRef] [PubMed]

43. Boehr, D.D.; Wright, P.E. Biochemistry. How do proteins interact? Science 2008, 320, 1429-1430. [CrossRef] [PubMed]

44. Kumar, S.; Ma, B.; Tsai, C.J.; Sinha, N.; Nussinov, R. Folding and binding cascades: Dynamic landscapes and population shifts. Protein Sci. 2000, 9, 10-19. [CrossRef] [PubMed]

45. Pan, Y.; Tsai, C.J.; Ma, B.; Nussinov, R. Mechanisms of transcription factor selectivity. Trends Genet. TIG 2010, 26, 75-83. [CrossRef] [PubMed]

46. Rodriguez, R.A.; Yu, L.; Chen, L.Y. Computing protein-protein association affinity with hybrid steered molecular dynamics. J. Chem. Theory Comput. 2015, 11, 4427-4438. [CrossRef] [PubMed]

47. Sotomayor, M.; Schulten, K. Single-molecule experiments in vitro and in silico. Science 2007, 316, 1144-1148. [CrossRef] [PubMed]

48. Giorgino, T. PLUMED-GUI: An environment for the interactive development of molecular dynamics analysis and biasing scripts. Comput. Phys. Commun. 2014, 185, 1109-1114. [CrossRef]

49. Zhang, Y.; Zhang, J.; Wang, W. Atomistic analysis of pseudoknotted RNA unfolding. J. Am. Chem. Soc. 2011, 133, 6882-6885. [CrossRef] [PubMed]

50. Short, F.L.; Akusobi, C.; Broadhurst, W.R.; Salmond, G.P.C. The bacterial Type III toxin-antitoxin system, ToxIN, is a dynamic protein-RNA complex with stability-dependent antiviral abortive infection activity. Sci. Rep. 2018, 8, 1013. [CrossRef] [PubMed]

51. Jorgensen, W.L.; Chandrasekhar, J.; Buckner, J.K.; Madura, J.D. Computer simulations of organic reactions in solution. Ann. N. Y. Acad. Sci. 1986, 482, 198-209. [CrossRef] [PubMed]

52. Zgarbova, M.; Otyepka, M.; Sponer, J.; Mladek, A.; Banas, P.; Cheatham, T.E., 3rd; Jurecka, P. Refinement of the cornell et al. nucleic acids force field based on reference quantum chemical calculations of glycosidic torsion profiles. J. Chem. Theory Comput. 2011, 7, 2886-2902. [CrossRef] [PubMed]

53. Duan, Y.; Wu, C.; Chowdhury, S.; Lee, M.C.; Xiong, G.; Zhang, W.; Yang, R.; Cieplak, P.; Luo, R.; Lee, T.; et al. A point-charge force field for molecular mechanics simulations of proteins based on condensed-phase quantum mechanical calculations. J. Comput. Chem. 2003, 24, 1999-2012. [CrossRef] [PubMed]

54. Bayly, C.I.; Cieplak, P.; Cornell, W.; Kollman, P.A. A well-behaved electrostatic potential based method using charge restraints for deriving atomic charges: The RESP model. J. Phys. Chem. 1993, 97, 10269-10280. [CrossRef]

55. Case, D.A.; Darden, T.A.; Cheatham, T.E., III; Simmerling, C.L.; Wang, J.; Duke, R.E.; Luo, R.; Walker, R.C.; Zhang, W.; Merz, K.M.; et al. Amber 12; University of California: San Francisco, CA, USA, 2012.

56. Darden, T.; York, D.; Pedersen, L. Particle mesh Ewald: An $N \log (N)$ method for Ewald sums in large systems. J. Comput. Phys. 1993, 98, 10089-10092. [CrossRef]

57. Ryckaert, J.P.; Ciccotti, G.; Berendsen, H.J.C. Numerical-integration of cartesian equations of motion of a system with constraints-molecular-dynamics of N-Alkanes. J. Comput. Phys. 1977, 23, 327-341. [CrossRef]

58. Gohlke, H.; Kiel, C.; Case, D.A. Insights into protein-protein binding by binding free energy calculation and free energy decomposition for the Ras-Raf and Ras-RalGDS complexes. J. Mol. Biol. 2003, 330, 891-913. [CrossRef]

59. Hu, G.; Wang, J. Ligand selectivity of estrogen receptors by a molecular dynamics study. Eur. J. Med. Chem. 2014, 74, 726-735. [CrossRef] [PubMed]

60. Hu, G.; Li, H.; Liu, J.Y.; Wang, J. Insight into conformational change for 14-3-3sigma protein by molecular dynamics simulation. Int. J. Mol. Sci. 2014, 15, 2794-2810. [CrossRef] [PubMed]

61. Chen, J.; Wang, J.; Zhu, W.; Li, G. A computational analysis of binding modes and conformation changes of MDM2 induced by p53 and inhibitor bindings. J. Comput. Aided Mol. Des. 2013, 27, 965-974. [CrossRef] [PubMed]

62. Weiser, J.; Shenkin, P.S.; Still, W.C. Approximate atomic surfaces from linear combinations of pairwise overlaps (LCPO). J. Comput. Chem. 1999, 20, 217-230. [CrossRef] 
63. Onufriev, A.; Bashford, D.; Case, D.A. Exploring protein native states and large-scale conformational changes with a modified generalized born model. Proteins 2004, 55, 383-394. [CrossRef] [PubMed]

64. Chen, L.Y. Thermodynamic integration in $3 n$ dimensions without biases or alchemy for protein interactions. bioRxiv 2017. [CrossRef]

65. Phillips, J.C.; Braun, R.; Wang, W.; Gumbart, J.; Tajkhorshid, E.; Villa, E.; Chipot, C.; Skeel, R.D.; Kale, L.; Schulten, K. Scalable molecular dynamics with NAMD. J. Comput. Chem. 2005, 26, 1781-1802. [CrossRef] [PubMed]

66. Chen, L.Y. Hybrid steered molecular dynamics approach to computing absolute binding free energy of ligand-protein complexes: A brute force approach that is fast and accurate. J. Chem. Theory Comput. 2015, 11, 1928-1938. [CrossRef] [PubMed]

67. Chen, L.Y. Nonequilibrium fluctuation-dissipation theorem of Brownian dynamics. J. Chem. Phys. 2008, 129, 144113. [CrossRef] [PubMed]

(C) 2018 by the authors. Licensee MDPI, Basel, Switzerland. This article is an open access article distributed under the terms and conditions of the Creative Commons Attribution (CC BY) license (http:/ / creativecommons.org/licenses/by/4.0/). 